\title{
Thermal performance of a two-phase thermosyphon energy storage system
}

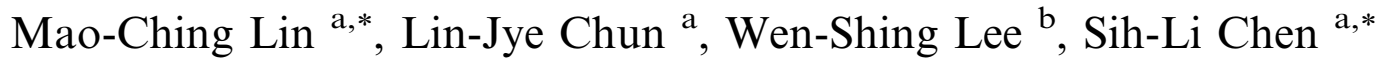 \\ a Department of Mechanical Engineering, National Taiwan University, 10673 Taipei, Taiwan, ROC \\ ${ }^{\mathrm{b}}$ Department of Air-conditioning and Refrigeration Engineering, National Taipei University of Technology, 10673 Taipei, Taiwan, ROC
}

Received 25 October 2002; accepted 11 August 2003

\begin{abstract}
This article presents an energy storage system, which can be readily integrated with the building structure. It stores heat supplied by solar energy via the two-phase closed loop thermosyphon to storage tank and releases stored heat in energy storage material via two-phase closed thermosyphon to the heat exchanger through the flow of transport fluid. The functions of such energy storage system have three operating modes, i.e., heat charge, heat discharge, and simultaneous charge and discharge. The thermal performance of the system with alcohol and water as working fluid is experimentally investigated. The results show that the storage system employing alcohol as working fluid in the loop thermosyphon provides better performance; the system gives optimum heat charge and discharge performance under $35-40 \%$ fill ratio, regardless whether the working fluid is water or alcohol. The system displays optimum charge efficiency of $73 \%$ and optimum discharge efficiency of $85 \%$ with alcohol as working fluid.
\end{abstract}

(c) 2003 Elsevier Ltd. All rights reserved.

\section{Introduction}

Sensible heat storage system utilizes water as energy storage material and stores heat through temperature increase of water. Because water is widely available and physically stable, such system has been extensively applied in homes, commerce and industry, particularly in the solar domestic hot water system, which works by storing thermal energy during the day under intense sunlight and releasing the stored heat at night or other time for use. Based on the heat transfer mechanisms inside the storage systems, they can be divided into two parts, i.e., single-phase (natural or forced circulation) and two-phase (thermosyphon) energy storage systems. Most of the energy storage designs cannot be integrated with the building structure, which occupy a lot of space and increase construction cost.

\footnotetext{
${ }^{*}$ Corresponding authors. Tel.: +886-2-23631808; fax: $+886-$ 2-23631755.

E-mail address: slchen01@ccms.ntu.edu.tw (S.-L. Chen).
}

Lavan and Thompson (1977) conducted experiment on single-phase hot water storage system. Such system entailed distributing hot water through piping and diffuser located above the storage tank and storing thermal energy in the storage tank by way of thermal stratification. Subsequent studies found that the turbulent mixing factor of the hydrodynamic disturbance at the outlet of diffuser and the geometrical dimensions of the storage tank played significant roles in system performance (Abdoly and Rapp, 1982; Oppel et al., 1986; Hariharan et al., 1991; Al-najem et al., 1993; Misra, 1994). With respect to two-phase thermosyphon applied in the energy storage system, McDonald et al. (1977) and Chen et al. (1990) investigated the characteristics of twophase closed loop thermosyphon through experimental method and studied the effect of fill ratio on evaporation, condensation and overall heat transfer coefficient.

The application of thermosyphon in solar energy system pertains mainly to solar collector (Young and Bergquam, 1981; Huang et al., 1983; Uhlemann and Bansal, 1985; Pluta and Pomierny, 1995). They studied the heat transfer characteristics and efficiencies of a two-phase thermosyphon system for solar collector 


\begin{tabular}{|c|c|c|c|}
\hline \multicolumn{4}{|c|}{ Nomenclature } \\
\hline$A$ & area $\left[\mathrm{m}^{2}\right]$ & $T_{\text {out }}$ & water outlet temperature $[\mathrm{K}]$ \\
\hline$c$ & specific heat $[\mathrm{J} / \mathrm{kg} \mathrm{K}]$ & $t$ & time $[\mathrm{s}]$ \\
\hline$c_{p}$ & specific heat at constant pressure $[\mathrm{J} / \mathrm{kg} \mathrm{K}]$ & $t_{\mathrm{op}}$ & operating time $[\mathrm{s}]$ \\
\hline$g$ & acceleration of gravity $\left[\mathrm{m} / \mathrm{s}^{2}\right]$ & $V_{\mathrm{r}}$ & actual volume of working fluid charged [ml] \\
\hline$h_{\mathrm{c}}$ & $\begin{array}{l}\text { condensation heat-transfer coefficient [W/ } \\
\left.\mathrm{m}^{2} \mathrm{~K}\right]\end{array}$ & $V_{\mathrm{t}}$ & total volume of thermosyphon $[\mathrm{ml}]$ \\
\hline$h_{\mathrm{fg}}$ & latent heat of evaporation $[\mathrm{J} / \mathrm{kg} \mathrm{K}]$ & \multicolumn{2}{|c|}{ Greek symbols } \\
\hline$L$ & length $[\mathrm{m}]$ & $\rho$ & density $\left[\mathrm{kg} / \mathrm{m}^{3}\right]$ \\
\hline$M$ & mass $[\mathrm{kg}]$ & $\mu$ & dynamic viscosity $[\mathrm{kg} / \mathrm{m} \mathrm{s}]$ \\
\hline$\dot{m}$ & mass rate $[\mathrm{kg} / \mathrm{s}]$ & $k$ & thermal conductivity $[\mathrm{W} / \mathrm{m} \mathrm{K}]$ \\
\hline$P_{\mathrm{g}}$ & vapor pressure $[\mathrm{Pa}]$ & $\Delta$ & variation of time \\
\hline$P$ & power $[\mathrm{W}]$ & \multicolumn{2}{|c|}{ Subscripts } \\
\hline$Q_{\mathrm{c}}$ & released heat at condensation side $[\mathrm{J}]$ & $\mathrm{c}$ & charge mode \\
\hline$Q_{\mathrm{ch}}$ & heat storage $[\mathrm{J}]$ & $\mathrm{d}$ & charge mode \\
\hline$Q_{\text {eff }}$ & effective heat $[\mathrm{J}]$ & $\mathrm{f}$ & liquid or fill ratio \\
\hline$Q_{\text {dis }}$ & discharge heat $[\mathrm{J}]$ & $\mathrm{g}$ & gas or vapor \\
\hline$Q_{\text {in }}$ & heat supply $[\mathrm{J}]$ & $i$ & count term or inner \\
\hline$Q_{1}$ & heat loss $[\mathrm{J}]$ & $j$ & time term \\
\hline$Q_{\text {sys }}$ & heat storage of system $[\mathrm{J}]$ & o & outer \\
\hline$R$ & thermal resistance $[\mathrm{K} / \mathrm{W}]$ & $\mathrm{p}$ & heating plate \\
\hline$R_{\mathrm{u}}$ & universal gas constant $[\mathrm{kJ} / \mathrm{kgmole} \mathrm{K}]$ & $\mathrm{s}$ & energy storage tank \\
\hline$T_{\text {in }}$ & water inlet temperature $[\mathrm{K}]$ & & \\
\hline
\end{tabular}

applications. The results showed that choosing suitable working fluid plays very important role in assuring proper operating condition of thermosyphon. In the analysis of thermal resistance of energy storage system, Konev et al. (1995) studied the characteristics of a heat exchanger based on a collector thermosyphon and found that the thermal resistance of such heat exchanger came from the evaporation section, piping for gas and fluid flow, and the condensation section.

The purpose of this paper is to present an energy storage system, which can be readily integrated with the architecture construction. It stores thermal energy from heating plate via two-phase closed loop thermosyphon to storage tank and releases the stored heat through two-phase closed thermosyphon to the heating load. Differing from the simple heat storage or simple heat discharge capacity of conventional storage system, this storage system incorporates three operating modes, i.e. heat charge, heat discharge and simultaneous heat charge and discharge. This study also examines the system performance with alcohol and water as working fluid respectively and the influence of fill ratio of the working fluid.

\section{Energy storage system descriptions}

Most of the simple energy storage systems utilize an active control method to store or release thermal energy.
That is, in the system design of thermal storage, a pump is included to transfer thermal energy from a high temperature heat source to the thermal storage tank via flowing working fluid. To utilize the stored thermal energy, an electromagnetic valve is used under control to change flow path of the working fluid, so that energy stored in the storage tank is released to and used by a low temperature heat sink. There are two drawbacks found in such type of thermal storage systems. First, the need of an operation cost and power consumption of pump. The thermal storage would be unworkable in case of a system failure. Second, change of the charge and discharge ability of the conventional simple storage systems is basically relied on the system piping design and therefore only two functions, i.e. energy storage and energy release, are available in its operating modes. It is impossible for both the heat supply side and the heat utilization side of the thermal storage to operate at the same time during the energy utilization.

As shown in Fig. 1, the energy storage system of this study features thermosyphon characteristics of twophase closed loop thermosyphon and two-phase closed thermosyphon. It comprises a heating plate (8) with vertical pipes (1), distributors (2), upper headers (3), fin tubes inside the energy storage tank (4), lower headers (5), and converge pipes (6). The upper headers (3) also work as a double pipe heat exchanger during heat release; the energy storage tank (7) contains two rows of fin tubes and has lower headers (5) arranged at its bot- 

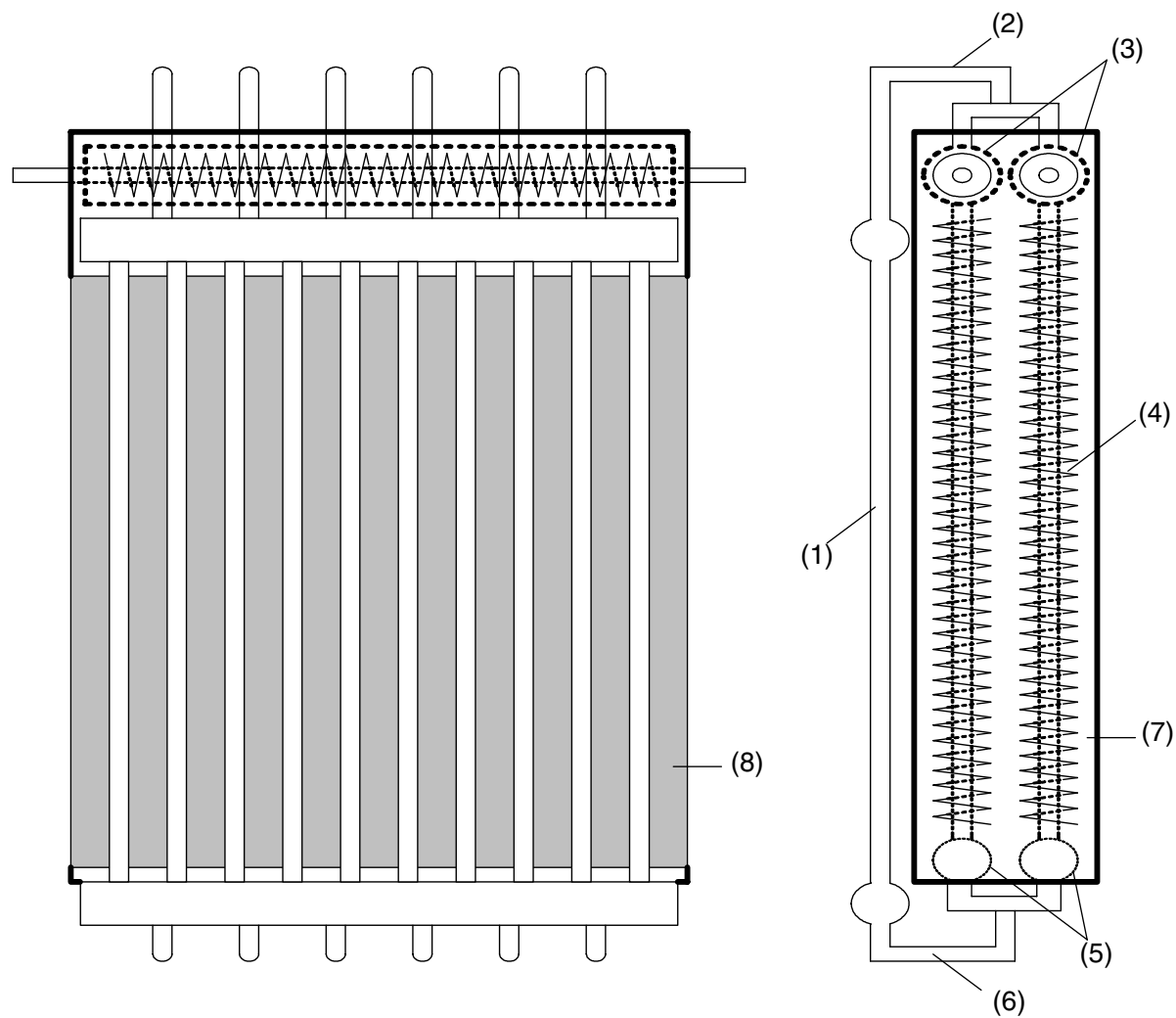

Fig. 1. Diagram of thermosyphon heat-pipe energy storage system: (1) vertical pipes, (2) distributors, (3) upper headers, (4) fin tubes, (5) lower headers, (6) converge pipes, (7) storage tank and (8) heating plate.

tom, which converge the working fluid in the fin tubes and send the fluid to converge pipe at the lower end of the system where the fluid is uniformly distributed before it returns to the vertical pipe (1). Water is used as energy storage material in the energy storage tank (7) and working fluid inside the loop thermosyphon may be alcohol or water.

The heat charge mode operates by the following principles: after the heating plate absorbs the heat, the working fluid in the adjacent vertical pipes undergoes boiling or evaporation (i.e. the evaporator side), and the gaseous inside the fin tubes transfers heat to the energy storage material (i.e. the condenser side). By virtue of gravity and density difference between vapor and fluid, the system will undergo heat charge automatically when the temperature of heating plate is higher than that of energy storage material in storage tank through twophase closed loop thermosyphon.

Heat discharge mode operates by the following principle: when the cold water enters the inside tube of the double pipe heat exchanger, the energy storage material will release heat due to the temperature disparity between it and cold water. The released heat from the energy storage material causes working fluid inside the vertical fin tubes to vaporize (i.e. the evaporator side). The gaseous working fluid undergoes condensation on the outside of fin tubes of double pipe heat exchanger (i.e. the condenser side), after heat is transferred to cold water passing. The system releases heat through the evaporation of working fluid inside vertical fin tubes and its condensation outside the fin tubes of double pipe heat exchanger by the action of two-phase closed thermosyphon.

The mechanism of simultaneous heat charge and discharge modes is initiated when there is thermal energy available for storage and heating load. In such event, the system can adjust the energy automatically based on the difference between available energy supply and load needs. If the thermal energy at supply side is greater than the needs at load side, working fluid vaporized at the vertical pipes will partly condense into fluid and transfer energy to double pipe heat exchanger. The remaining vapor will release excess heat to energy storage material through the vertical fin tubes in the storage tank. When the supply-side thermal energy is less than the heating load, the required load to heat the water in double pipe heat exchanger will be supplied simultaneously from vertical pipes and energy storage material in the storage 
tank. If the supply-side thermal energy is equal to heating load, the needs will be met directly by the supply-side thermal energy without drawing heat stored in the storage tank.

The distinguishing feature of present energy storage system can make the thickness of energy storage system thinner and the weight of storage tank lighter, as compared with the conventional heating system. Thus the cubic configuration of present design could be utilized in many occasions where the conventional solar collectors cannot be applied. For instance it can integrate with the architecture construction to be installed as the wall or roof of the building, which can sufficiently utilize the space of building and to reduce the solar heating load to the building. It is much suitable at Taiwan where the cooling load for air conditioner comes mostly from the solar heating.

It is also suitable for the regions where the water quality is very poor; for example, at the south part of Taiwan people use solar energy to heat the underground water. The fur would take place inside the energy storage tank in the conventional solar collectors; which result in bad heat transfer and corrosion problems. In the present energy storage system, double pipe heat exchanger is used to release the stored heat from the energy storage tank to the cold water of used side. It can prevent the corrosion inside the storage tank.

\section{Experimental investigation}

The equipment for this experimental study was comprised of energy storage system and measuring system. The former consisted of a heat source (including absorber plates), energy storage tank (including two rows of fins), and a double pipe heat exchanger; the latter consisted of thermocouples, recorder and data acquisition system.

The heating section at supply side of heat source consisted of absorber plates made of very thin copper and 10 vertical copper tubes. Foil heaters were adhered to the heating section to simulate the solar energy. The energy storage tank was made of $3 \mathrm{~mm}$ thick stainless steel plates, in which two rows of fin tubes, 18 fins each, were mounted. Two headers each were connected at top and bottom of the storage tank, where the two upper headers were copper tube sealed with cooper stoppers on both ends and contained internal stainless steel fins working also as double pipe heat exchanger during heat discharge. The use of double-row fins in the energy storage tank increased heat transfer area during heat charge and discharge. Water with total volume of 1821 was used as energy storage material in the tank. Throughout the course of experiment, heating plate at supply side of heat source and the exterior of energy storage tank were covered with insulation material to prevent heat loss resulting from temperature difference between the surroundings and the system. The double pipe heat exchanger used copper tubing outside and stainless fin tube inside to avoid build-up and corrosion problems. The fins at the exterior of stainless tube increased the heat transfer area to help compensation and increase the heat transfer efficiency. During heat charge, heat input was achieved by connecting the AC power supply to foil heater; during heat discharge, heat output was carried out using hot-water exchanger located at the top of storage tank by adjusting the flow of cool water passing through hot-water exchanger. The sizes of equipment used in the experiment are depicted in Table 1.

Fig. 2 is a schematic of measuring apparatuses used in the experiment for obtaining the physical quantity of primarily temperature and water flow, supplemented by data of pressure. Temperature measurement utilized Ttype thermocouple with $0.3 \mathrm{~mm}$ probe and recorder (YOKOGAWA HR2300). Temperature measurement points included five points (T1-T5) for temperature of working fluid inside upper and lower headers of energy storage tank and upper and lower connecting tubes at supply side of heat source; four points (T6-T9) on walls of upper header; three points (T10-T12) on fins of energy storage tank at different locations of the same level; six points (T13-T18) on energy storage material; and two points each (T19-T22) at inlet and outlet of double pipe heat exchanger to measure the water temperatures.

Table 1

The sizes of equipment used in the experiment

\begin{tabular}{lll}
\hline Name & Size & Unit \\
\hline Supply side & & \\
Area of absorber plate & 0.9 & $\mathrm{~m}^{2}$ \\
Thickness of heating plate & 1 & $\mathrm{~mm}$ \\
Length of heat pipe & 1050 & $\mathrm{~mm}$ \\
External diameter of heat pipe & 12.7 & $\mathrm{~mm}$ \\
Energy storage tank & & \\
Length of fin tube & 850 & $\mathrm{~mm}$ \\
External diameter of fin tube & 19 & $\mathrm{~mm}$ \\
Height of fin & 9 & $\mathrm{~mm}$ \\
Gap of fin & 9 & $\mathrm{~mm}$ \\
Thickness of stainless steel & 2.5 & $\mathrm{~mm}$ \\
Thickness of insulation material & 19 & $\mathrm{~mm}$ \\
Volume & 182 & 1 \\
Hot water heat exchanger & & \\
Length of fin tube & 850 & $\mathrm{~mm}$ \\
External diameter of fin tube & 19 & $\mathrm{~mm}$ \\
Height of fin & 9 & $\mathrm{~mm}$ \\
Gap of fin & 9 & $\mathrm{~mm}$ \\
Length of outer heater & 970 & $\mathrm{~mm}$ \\
External diameter of outer heater & 2.125 & $\mathrm{in}$. \\
\hline
\end{tabular}




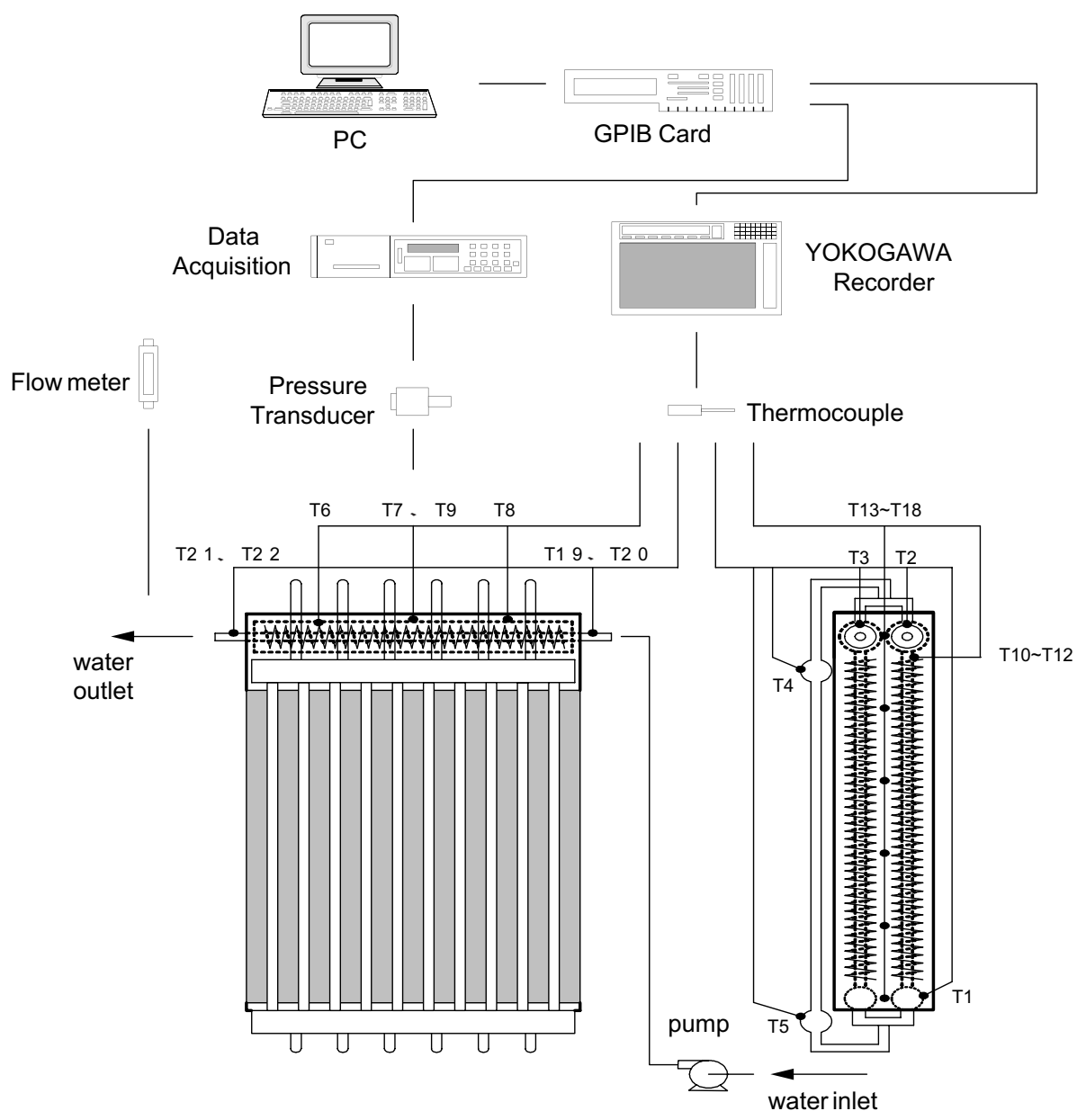

Fig. 2. Schematic of measuring apparatuses used in the experiment.

The first task in the experiment was charging the working fluid, after which all valves, except that connecting to the vacuum pump, were closed. It was found that when the system was near vacuumed state, the volume of working fluid drained from the loop thermosyphon was less than that originally charged. Further exploration of the cause found that small amount of working fluid steam was pumped out during vacuum, resulting in error of approximately $0.5 \%$.

The ratio of filling working fluid (fill ratio) in thermosyphon, expressed by volume percentage, may be defined as follows:

$V_{\mathrm{f}}=\frac{V_{\mathrm{r}}}{V_{\mathrm{t}}} \times 100 \%$

where $V_{\mathrm{r}}$ is the actual volume of working fluid charged, $V_{\mathrm{t}}$ the total volume of thermosyphon, which was 14,468 $\mathrm{ml}$ by actual measurement. The fill ratio for this part of experiment ranged between $35 \%$ and $60 \%$, meaning 4640.4 to $9280.8 \mathrm{ml}$ of fluid were charged.

\section{Results and discussion}

The experiments consist of three parts: Part 1 entailed simple heat charge and simple heat discharge experiments that tested heat storage into storage tank through working fluid in the two-phase closed loop or closed thermosyphon under constant fill ratio; Part 2 studied the influence of different working fluids (alcohol and water) and fill ratios (35-60\%) on system performance; and Part 3 explored whether the system displayed the anticipated function of automatic charge and discharge adjustment under different loads. A summary of the working conditions for the experiments is depicted in Table 2.

\subsection{Simple heat storage and simple heat discharge experiments}

The system utilized thermosyphon to undergo heat charge and discharge respectively in this experiment that 
Table 2

Table of the working conditions for the experiments

\begin{tabular}{|c|c|c|c|}
\hline \multirow[t]{2}{*}{ Items } & \multicolumn{3}{|l|}{ Name of experiment } \\
\hline & $\begin{array}{l}\text { Simple heat storage and } \\
\text { simple heat discharge }\end{array}$ & $\begin{array}{l}\text { The influence of working } \\
\text { fluid on system perfor- } \\
\text { mance }\end{array}$ & $\begin{array}{l}\text { Simultaneous heat storage } \\
\text { and heat discharge }\end{array}$ \\
\hline Working fluid & Alcohol & Alcohol/water & Alcohol \\
\hline Fill ratio $(\%)$ & 40 & $35-60$ & 40 \\
\hline \multicolumn{4}{|l|}{ Heat storage process } \\
\hline Heat input $(\mathrm{W})$ & 1300 & 1300 & 1300 \\
\hline Operating time $(\mathrm{h})$ & 8 & 4 & 6 \\
\hline \multicolumn{4}{|l|}{ Discharge process } \\
\hline Heat input (W) & - & - & 1300 \\
\hline Operating time $(\mathrm{h})$ & 3 & 2 & 3 \\
\hline \multirow[t]{2}{*}{ Water flow rate $\left(\mathrm{m}^{3} / \mathrm{s}\right)$} & $5 \times 10^{-5}$ & $5 \times 10^{-5}$ & $8.33 \times 10^{-5}(1.5 \mathrm{~h})$ \\
\hline & & & $2.33 \times 10^{-5}(1.5 \mathrm{~h})$ \\
\hline
\end{tabular}

aimed to study temperature distribution of working fluid in the thermosyphon and of energy storage material in the storage tank. The operating conditions for the experiment were $40 \%$ fill ratio, alcohol as working fluid, water as energy storage material, and $1300 \mathrm{~W}$ of heat input to undergo $8 \mathrm{~h}$ of heat storage; in case of heat discharge, water flow rate at $5 \times 10^{-5} \mathrm{~m}^{3} / \mathrm{s}$ to undergo $3 \mathrm{~h}$ of discharge.

The results for this part of experiment are illustrated in Figs. 3-6. As shown in Fig. 3 depicting temperature variation of working fluid in the two-phase closed loop thermosyphon, temperature measured at lower header of storage tank (T1) was the lowest. That is because the

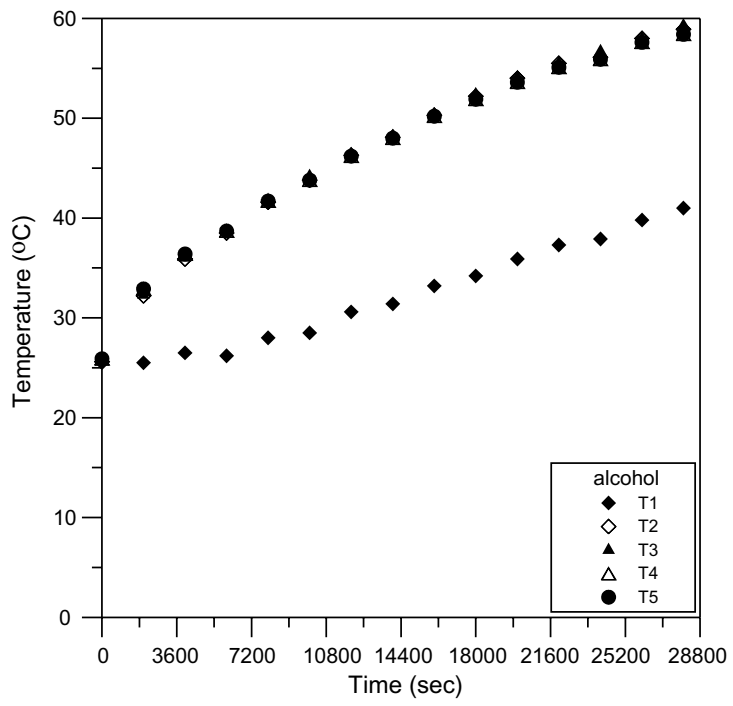

Fig. 3. The temperature variation in the header during heat storage.

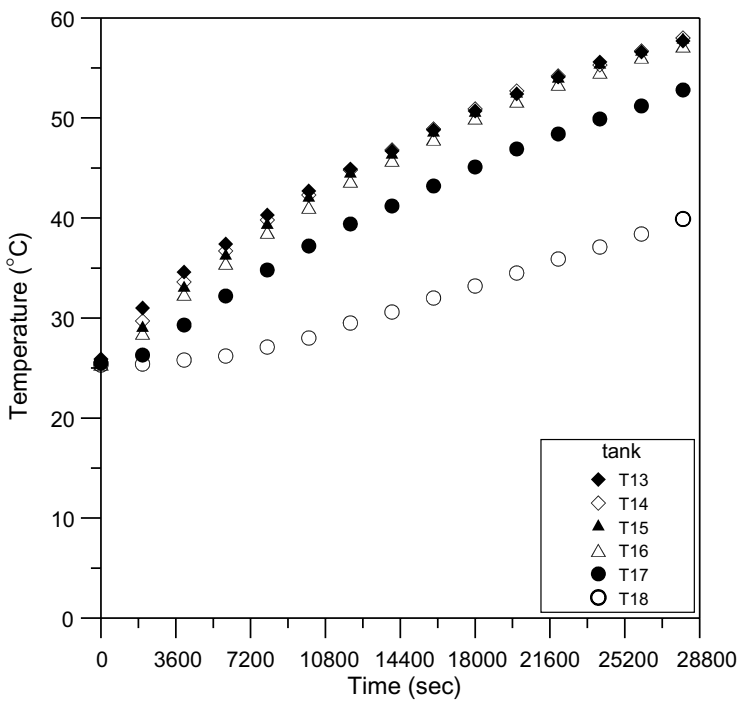

Fig. 4. The temperature variation of energy storage material inside the tank during heat storage.

steam of working fluid was condensed in the fin tubes inside the tank to release heat to energy storage material before returning to supply-side of heat source. But as the system absorbed heat continuously, temperature of working fluid in the thermosyphon rose gradually. The temperature of working fluid at lower connecting tube (T5) and upper connecting tube (T4) of supply-side of heat source, and at upper headers (T2 and T3) of storage tank varied little, indicating small thermal resistance in two-phase closed loop thermosyphon from its evaporation section to condensation section. Therefore it allows the heated working fluid in evaporation section to reach condensation section rapidly and release heat to energy storage material (Hijikata et al., 1989). 


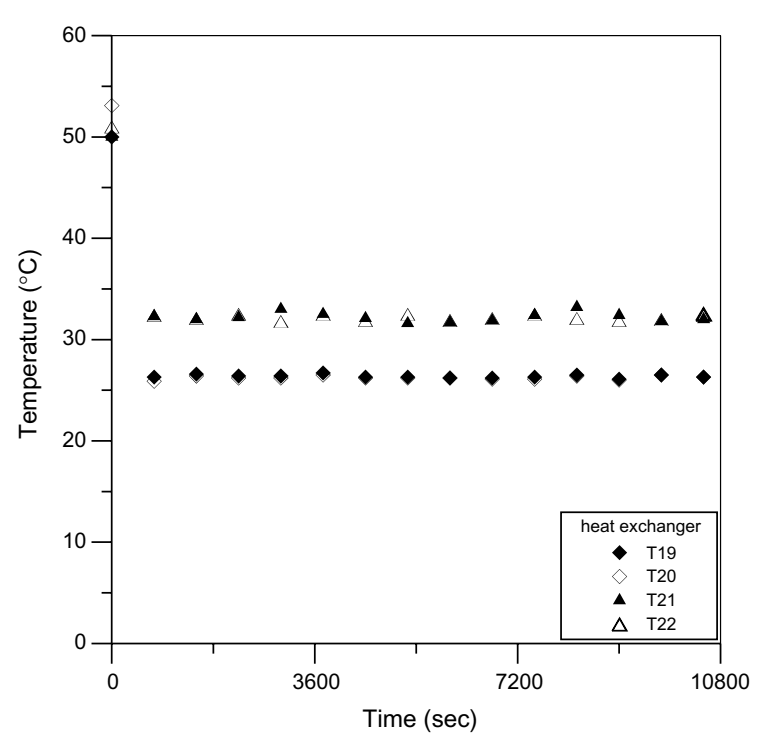

Fig. 5. The temperature variation of water inlet/outlet of double pipe exchanger during heat discharge.

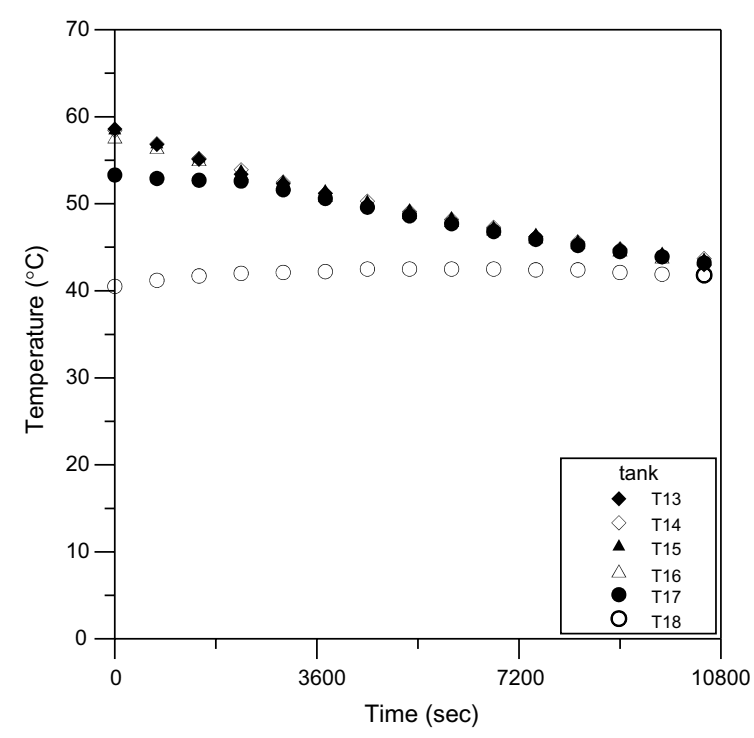

Fig. 6. The temperature variation of energy storage material inside the tank during heat discharge.

It is also observed that wall temperatures at left, middle and right parts of upper header of storage tank (T6-T8) approximated each other, so did temperatures of upper header on top of fin tubes (T7 and T9). It can be deduced that in the two-phase closed loop thermosyphon, gaseous working fluid from upper connecting tube of supply-side heat source was evenly distributed in the upper header of storage tank and then released thermal energy through condensation.
In addition, temperatures of fins at left, middle and right on the same level in the storage tank (T10-T12) were also close. Thus in calculating stored heat or released heat in the storage tank, the system may be considered as one-dimensional model.

Temperature variation of energy storage material during heat storage is illustrated in Fig. 4. Of the six measurement points (T13-T18), energy storage material near upper and lower header exhibited the highest and lowest temperature respectively, while four points in the middle were evenly distributed. It is also observed that energy storage material displayed mild thermal stratification where heat storage was satisfactory from $\mathrm{T} 13$ to T17, but not as desirable at the lowest point, i.e. T18.

In the sensible heat storage system, the thermal stratification will occur due to the density disparity of energy storage material. In present study, at the higher fill ratio conditions, the length of effective condenser section inside the two-phase closed loop thermosyphon becomes shorter. Therefore, the energy storage material at the upper region inside the storage tank will absorb more thermal energy than the lower region, which causes larger temperature difference between upper and lower regions. However, in the present study, it is found that there exists an optimal fill ratio of working fluid in this energy storage system. Under this condition, the temperature difference of energy storage material is small and the stored thermal energy is large. The thermal stratification in this energy storage system is not so serious as compared with the normal heat storage. Another effective method to reduce the thermal stratification effect is to use the wick structure in the evaporator section (i.e., loop heat pipe). The capillary force from the wick structure during evaporation can increase the effective condenser area, which can reduce the thermal stratification in the energy storage tank.

Fig. 5 shows temperature variation at water inlet/ outlet of double pipe heat exchanger during heat discharge. The system had two double pipe heat exchangers installed and each heat exchanger had an inlet (T19 and T20) and an outlet (T21 and T22). It is observed that under water flow of $5 \times 10^{-5} \mathrm{~m}^{3} / \mathrm{s}$, the system released heat in a stable manner to meet the needs of heating load. Fig. 6 depicts temperature variation of energy storage material in the storage tank during heat discharge. Same as the time of heat storage, energy storage material also displayed thermal stratification during heat discharge, only the small temperature variation in the first five measurement points (T13-T17) were consistent, suggesting system stability.

\subsection{Experimental study on the influence of working fluid on system performance}

Thermosyphon undergo the cycle of heat absorption and release through passage of working fluid in the 
evaporation section and condensation section. Thus the choice of working fluid has significant influence on thermosyphon performance. In addition, the fill ratio of working fluid is also an important parameter of system performance. As shown in Table 2, the operating conditions for this part of experiment were $35-60 \%$ fill ratio, alcohol and water as working fluid, $1300 \mathrm{~W}$ of heat input to undergo $4 \mathrm{~h}$ of heat charge; in case of heat discharge, water flow rate at $5 \times 10^{-5} \mathrm{~m}^{3} / \mathrm{s}$ to undergo $2 \mathrm{~h}$ of discharge. The results of this experiment are illustrated in Figs. 7-11, in which the rhombic points are calculations based on experimental results and the curves are trend lines from regression of data. Stored heat of the system $Q_{\text {ch }}$ may be computed based on temperature rise of the energy storage material $\left(\Delta T_{i, j}\right)$,

$Q_{\mathrm{ch}}=\sum_{j=0}^{t} \sum_{i=1}^{6} M_{\mathrm{s}} c_{p} \Delta T_{i, j}$

where $\Delta T_{i, j}=\left(T_{i, j+\Delta t}-T_{i, j}\right)$.

Fig. 7 displays variation of stored energy under different working fluids and fill ratios. As shown, there existed an optimum value of $40 \%$ fill ratio for maximum energy stored. This is because at smaller fill ratios, the longer section, i.e. larger area in fin tubes for condensation allows more energy storage material in the storage tank to absorb the heat released from condensation, resulting in greater stored heat. But if the fill ratio is too small, the thermal energy from supply-side of heat source might have difficulty undergoing boiling heat transfer. The thermosyphon tends to dry up under low fill ratio, which diminishes its heat storage performance.

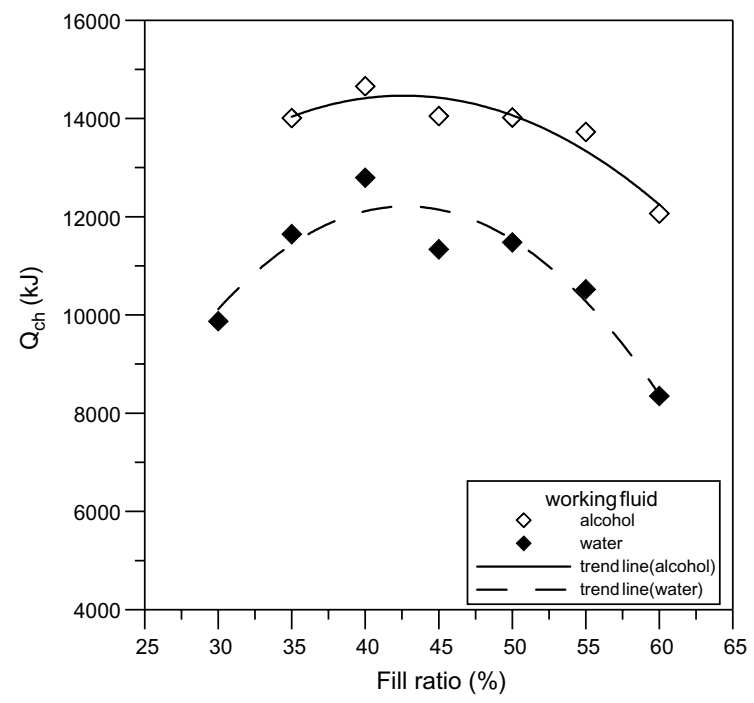

Fig. 7. Comparison of stored energy under different working fluid and fill ratio.

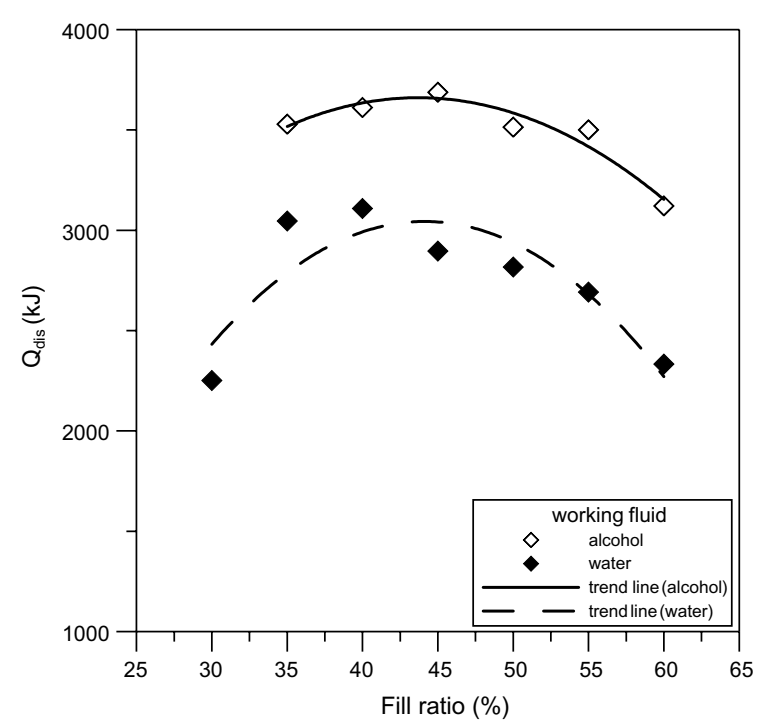

Fig. 8. Comparison of heat discharge under different working fluid and fill ratio.

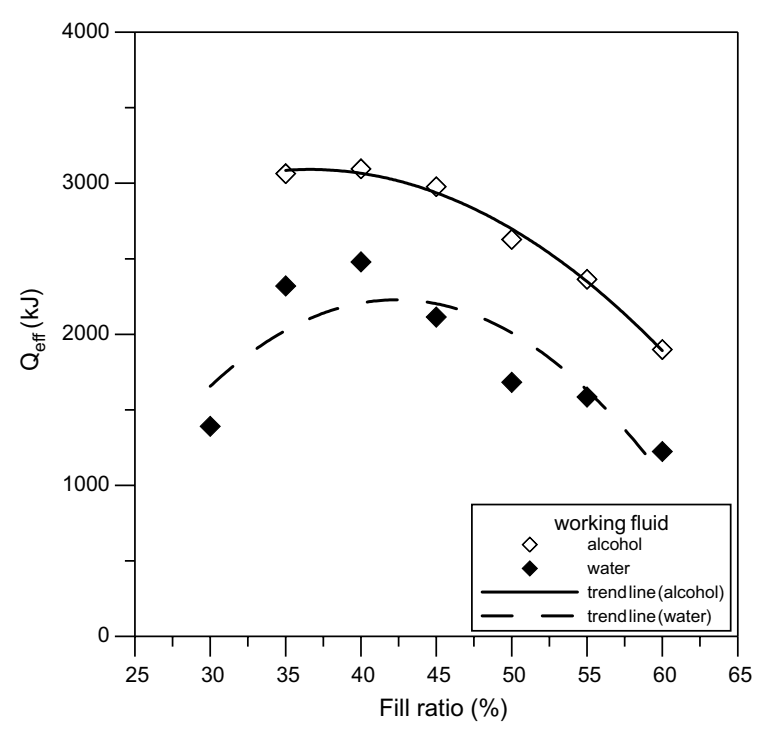

Fig. 9. Comparison of effective heat output under different working fluid and fill ratio.

Theoretically gaseous working fluid undergoes primarily film condensation during heat release and its coefficient of conductivity may be derived from the Nusselt's Film Theory Condensation as proposed by Nusselt solution (Holman, 1992) as follows:

$h_{\mathrm{c}}=0.943\left(\frac{k_{\mathrm{f}}^{3} \rho_{\mathrm{f}}\left(\rho_{\mathrm{f}}-\rho_{\mathrm{g}}\right) g h_{\mathrm{fg}}}{\mu_{\mathrm{f}} \Delta T_{\mathrm{c}} L_{\mathrm{c}}}\right)^{\frac{1}{4}}$ 


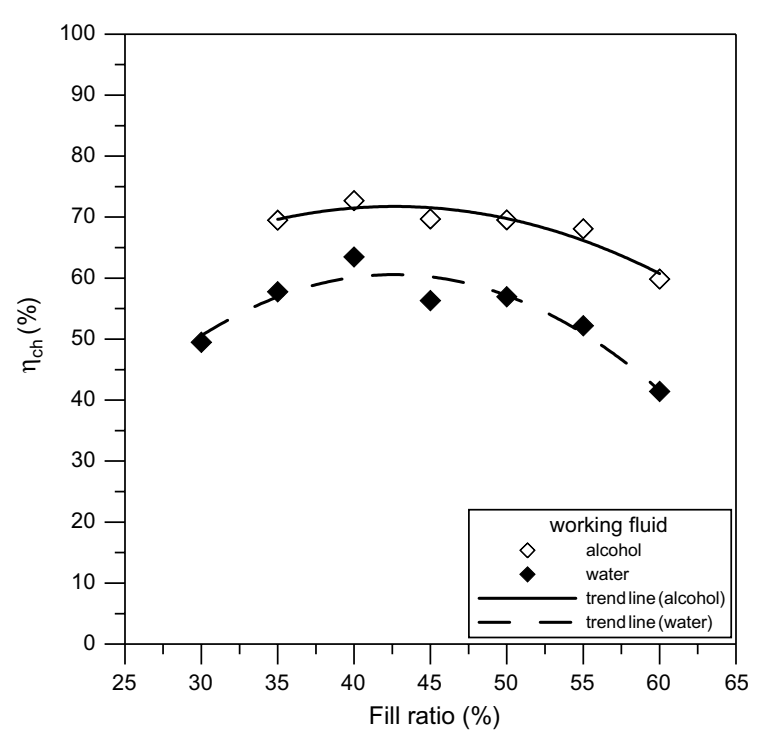

Fig. 10. Comparison of the heat storage efficiency under different working fluid and fill ratio.

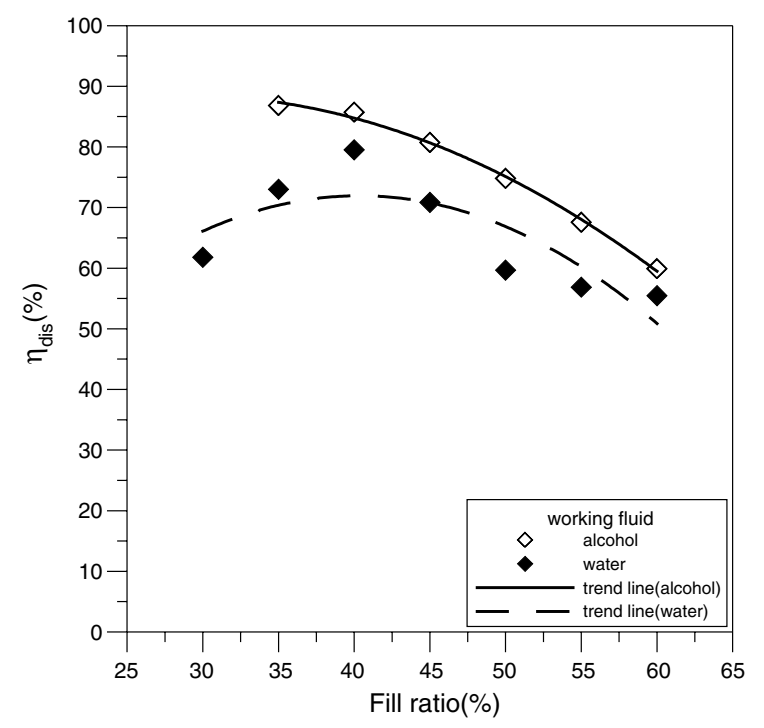

Fig. 11. Comparison of the heat discharge efficiency under different working fluid and fill ratio.

where $\Delta T_{\mathrm{c}}$ is the difference between condensation temperature of working fluid and wall temperature of fin tubes. Assuming all thermal energy released from condensation is transferred to energy storage material radially through fin tubes, then the relationship between released heat and $\Delta T_{\mathrm{c}}$ may be expressed as follows:

$Q_{\mathrm{c}}=h_{\mathrm{c}} A_{\mathrm{c}} \Delta T_{\mathrm{c}}$
From Eqs. (3) and (4), we may obtain

$Q_{\mathrm{c}}=0.943\left(\frac{k_{\mathrm{f}}^{3} \rho_{\mathrm{f}}\left(\rho_{\mathrm{f}}-\rho_{\mathrm{g}}\right) g h_{\mathrm{fg}}}{\mu_{\mathrm{f}} L_{\mathrm{c}}}\right)^{\frac{1}{4}}\left(\Delta T_{\mathrm{c}}\right)^{\frac{3}{4}}$

Thus under the same working fluid and same amount of thermal energy released from the condensation of gaseous working fluid, higher fill ratio of working fluid results in bigger $\Delta T_{\mathrm{c}}$ due to smaller length of condensation, that is, lower wall temperature of fin tubes brings about less heat storage in energy storage material.

Energy calculated in heat discharge includes effective heat output $Q_{\text {eff }}$ and discharged heat $Q_{\text {dis }}$. $Q_{\text {dis }}$ may be obtained from temperature drop of energy storage material $\left(\Delta T_{i, j}\right)$,

$Q_{\mathrm{dis}}=\sum_{j=0}^{t} \sum_{i=1}^{6} M_{\mathrm{s}} c_{p} \Delta T_{i, j}$

Effective heat output $Q_{\text {eff }}$ means energy actually derived at the load, which may be obtained from temperature difference between the water inlet and outlet of double pipe heat exchanger $\left(\Delta T_{w, j}\right)$,

$Q_{\text {eff }}=\sum_{j=0}^{t} \dot{m} c \Delta T_{w, j} \Delta t$

where $\Delta T_{w, j}=\left(T_{w, \text { out }}-T_{w, \text { in }}\right)$, time variance $\Delta t$ was $10 \mathrm{~s}$.

Fig. 8 illustrates variation of heat discharge from the storage tank under different working fluids and fill ratios. It is shown that the system exhibited optimum heat discharge at $40 \%$ and $45 \%$ fill ratios. Since the heat discharge experiment was conducted immediately after heat storage experiment, temperature distribution of energy storage material in the storage tank upon the completion of storage test would have a bearing on system performance of heat discharge. Under lower fill ratio, energy storage material released more heat. As shown in Fig. 9, the system performed better at fill ratio of $40 \%$ judging from the heat absorbed by water at double pipe heat exchanger, regardless whether the working fluid was alcohol or water.

Thus we can define two system-related efficiencies, i.e. heat storage efficiency and heat discharge efficiency. The former is the ratio of stored heat in energy storage material to heat input from power supply; the latter is the ratio of effective absorbed heat of double pipe heat exchanger to heat released from energy storage material, which are expressed as follows:

$\eta_{\mathrm{ch}}=\frac{Q_{\mathrm{ch}}}{Q_{\mathrm{in}}}$

$\eta_{\text {dis }}=\frac{Q_{\text {eff }}}{Q_{\text {dis }}}$

where $Q_{\text {in }}$ (heat supply) is the product of electric power of power supply and time,

$Q_{\text {in }}=P \cdot t_{\text {op }}$ 
The energy balance equations of energy storage system for the charge mode and discharge mode are

$Q_{\mathrm{in}}=Q_{\mathrm{ch}}+Q_{\mathrm{lc}}$

$Q_{\text {disch }}=Q_{\text {eff }}+Q_{\text {dd }}$

For the case of charge mode, the heat losses of the energy storage system, $Q_{\mathrm{lc}}$, include the heat loss of energy storage tank $Q_{\mathrm{lcs}}$, and the heat loss from heating plate to surrounding $Q_{\mathrm{lcp}} . Q_{\mathrm{lcs}}$ is calculated from the heat loss coefficient of energy storage tank, the area of energy storage system and the temperature difference between energy storage material and surrounding. $Q_{\text {lcp }}$ can be obtained from the heat input minus the stored heat and heat loss of energy storage tank.

It is assumed that the heat loss coefficient of the energy storage tank remains constant and can be calculated from the thermal resistance analysis. We can obtain that the heat loss coefficient is $1.34 \mathrm{~W} / \mathrm{m}^{2} \mathrm{~K}$. Therefore the heat loss of energy storage tank will depend upon the average temperature of energy storage material. Table 3 shows the effect of different fill ratio and working fluid on charge efficiency and heat loss percentage. The heat loss percentage of energy storage tank is $0.60 \%$ for alcohol, where the charge efficiencies are $73 \%$ and $60 \%$ at $40 \%$ and $60 \%$ fill ratio. Similar results of heat loss percentage for water are also shown in Table 3. For this reason, heat loss of energy storage tank is very small and can be neglected.

Table 3 also indicates that the heat loss percentages of heating plate are $26.39 \%$ and $39.4 \%$ for alcohol, where the fill ratios are at $40 \%$ and $60 \%$. The corresponding charge efficiencies are $73 \%$ and $60 \%$ respectively. It is obvious that under lower fill ratio condition, the effective condenser area is larger and the condensation effect is better. However, since the working fluid inside the heating plate transfers less thermal heat to energy storage material, it will make the temperature of heating plate become higher. Therefore, the heat loss of heating plate is higher. Under the higher fill ratio condition, the condensation effect of working fluid is poor due to short length of condenser. It will make the temperature of working fluid remain higher and result in the

\section{Table 3}

The effect of different fill ratio and working fluid on charge efficiency and heat loss percentage

\begin{tabular}{llll}
\hline Fill ratio, working fluid & $\eta_{\text {ch }}$ & $Q_{\text {lcs }} / Q_{\text {in }}$ & $Q_{\text {lcp }} / Q_{\text {in }}$ \\
\hline $40 \%$, water & $66 \%$ & $0.60 \%$ & $33.4 \%$ \\
$60 \%$, water & $42 \%$ & $0.60 \%$ & $57.4 \%$ \\
$40 \%$, alcohol & $73 \%$ & $0.61 \%$ & $26.39 \%$ \\
$60 \%$, alcohol & $60 \%$ & $0.60 \%$ & $39.4 \%$ \\
\hline
\end{tabular}

higher temperature of heating plate. Therefore, it exists an optimal fill ratio to minimize the heat loss of heating plate.

As shown in Fig. 10, the system with alcohol as working fluid had highest storage efficiency of $73 \%$ at $40 \%$ fill ratio; with water as working fluid, it exhibited better storage efficiency at fill ratios ranging from $40 \%$ to $50 \%$. Fig. 11 indicates that discharge efficiency with alcohol as working fluid showed near linear drop and it has highest discharge efficiency of $85 \%$ at $35 \%$ fill ratio. With water as working fluid, discharge efficiency was better at fill ratios between $35 \%$ and $45 \%$.

As shown in Fig. 7-11, alcohol generally performs better than water. It should be noted that water and alcohol were chosen as the working fluid, since they are compatible with copper and safe materials to work with. Due to the difference thermal characteristics between alcohol and water, there was different performance with them. The boiling temperature of water and alcohol at atmospheric pressure is 100 and $78.6^{\circ} \mathrm{C}$. The latent heat of evaporation is $2258 \mathrm{~kJ} / \mathrm{kg} \mathrm{K}$ for water and is $847 \mathrm{~kJ} /$ $\mathrm{kg} \mathrm{K}$ for alcohol. Due to the smaller latent heat of alcohol, the mass flow rate of vapor at the evaporation section is larger than that of water at the same thermal heat input. The response time for thermal storage is faster for alcohol than that for water. It is the recommended working fluid for the two phase closed thermosyphon.

The inclination angle may influence the performance of energy storage system. In the present study, all the experiments were made for the $90^{\circ}$ position to simulate the application of solar collector integrated with the wall structure. It shows that the system had better efficiency at $40 \%$ fill ratio, regardless whether the working fluid is alcohol or water. If the system is applied to integrate with roof structure with an inclination angle, the optimal fill ratio may not be $40 \%$. At the inclined position, the effective length of both evaporator and condenser becomes shorter, as compared with the $90^{\circ}$ position, which results in reducing the charge efficiency.

\subsection{Experimental study on simultaneous heat charge and heat discharge}

This experiments probed whether the system was capable of adjusting automatically heat charge and discharge based on the principle of thermal equilibrium under heat supply (with steady input of heat) and different loads (different water flow rates). The operating conditions for the experiment were $40 \%$ fill ratio, alcohol as working fluid, water as energy storage material, and $1300 \mathrm{~W}$ of heat input to undergo $8 \mathrm{~h}$ of heat storage; in case of heat discharge, $1300 \mathrm{~W}$ of heat input. The operation in this experiment had two stages; in the first $5400 \mathrm{~s}(1.5 \mathrm{~h})$, thermal energy was transferred from heat source to energy storage material and double pipe heat 
exchanger at high flow rate of $8.33 \times 10^{-5} \mathrm{~m}^{3} / \mathrm{s}$; in the second $5400 \mathrm{~s}$, thermal energy was transferred from heat source and energy storage material to double pipe heat exchanger at low water flow rate of $2.33 \times 10^{-5} \mathrm{~m}^{3} / \mathrm{s}$.

The temperature variation of energy storage material during heat discharge is depicted in Fig. 12. Under high flow rate $8.33 \times 10^{-5} \mathrm{~m}^{3} / \mathrm{s}$ and heat discharge for a duration of $1.5 \mathrm{~h}$, heating load was bigger than heat supply and the deficiency was made up by energy storage material in the storage tank, which caused temperature drop of energy storage material with time. However the temperature of no. 6 measurement point (T18) rose gradually as time elapsed during heat discharge due to the fact that temperature of thermosyphon was still higher than that of energy storage material around this point. During heat discharge at low flow rate of $2.33 \times 10^{-5} \mathrm{~m}^{3} / \mathrm{s}$, excess heat from heat source after supplying the smaller heating load will be stored in the energy storage material. This phenomenon is manifested by the fact that the temperature of measurement points 1-3 (T13-T15), as shown in the graph, rose after $1.5 \mathrm{~h}$ (5400 s).

Given that the system supplied and demanded energy at the same time under this operation, the computation of its energy variation requires some modification; its heat supply $Q_{\text {in }}$ may be obtained from Eq. (12); its effective heat output $Q_{\text {eff }}$ may be obtained from Eq. (9), while system energy variation $Q_{\text {sys }}$ may be obtained from the following equation:

$Q_{\mathrm{sys}}=\sum_{j=0}^{t} \sum_{i=1}^{6} M_{\mathrm{s}} c_{p} \Delta T_{i, j}$

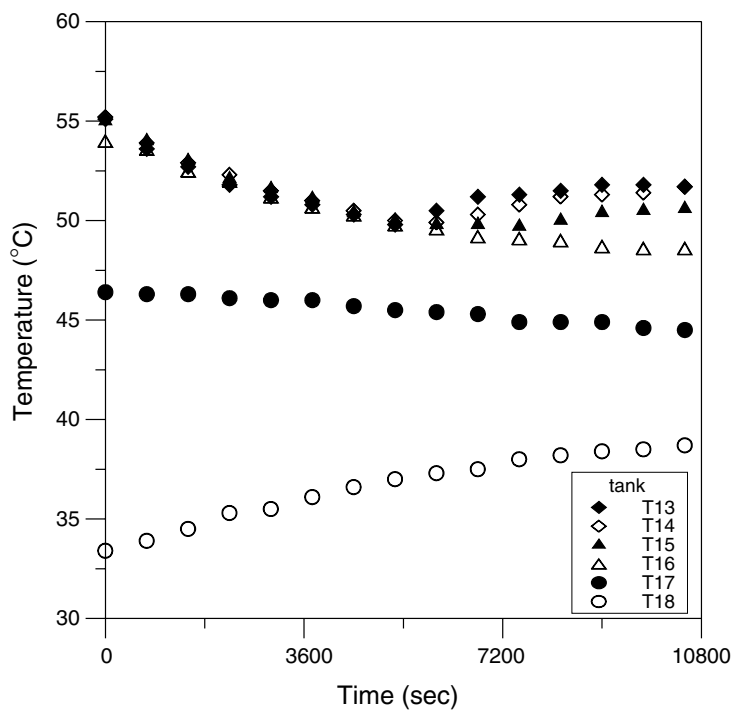

Fig. 12. The temperature variation of energy storage material during heat discharge.

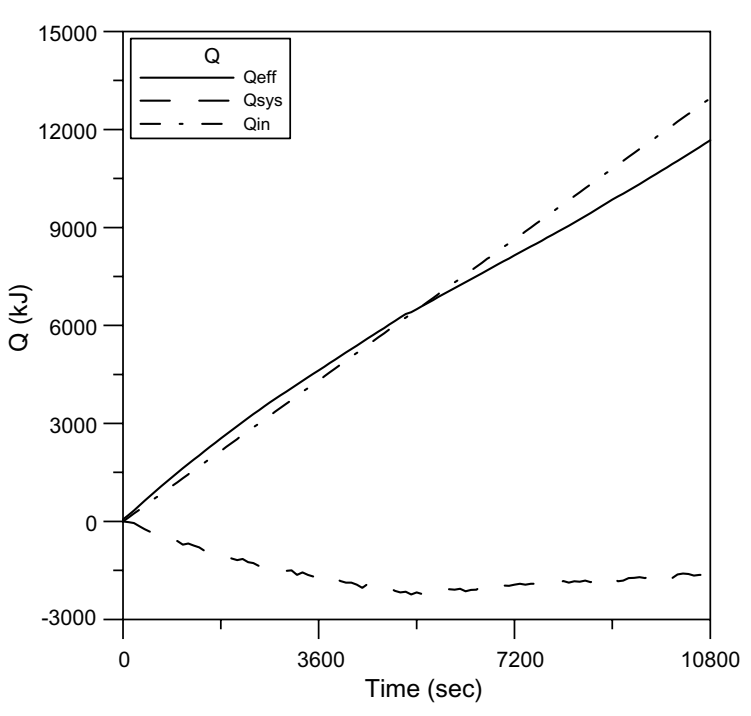

Fig. 13. The variation of each heat on simultaneous heat storage and heat discharge.

From Fig. 12, we can only learn the system function of automatic adjustment qualitatively in lieu of quantitatively. But Fig. 13 provides supplemental information. It is seen that when the heating load was greater than heat supply, the stored energy in energy storage material dropped to make up the deficiency; when heat supply was greater than heating load, energy storage material stored excess heat in the storage tank, boosting the stored energy in the tank, thus indicating that the system did have the anticipated function of automatic adjustment.

\section{Conclusion}

Based on the experiments and results just discussed, following conclusions may be drawn regarding the energy storage system:

1. As experimentally verified, the present energy storage system performs three modes, i.e. simple heat storage, simple heat discharge and simultaneous heat storage and discharge.

2. The system performs better with alcohol as working fluid in the loop thermosyphon than water, indicating that working fluid is a factor to be taken into account in the design of such an energy storage system.

3. A proper fill ratio range exists for the optimum performance of the energy storage system, regardless whether the working fluid is alcohol or water. Under the operating conditions of this study, the proper range is $35-40 \%$. 
4. The optimum heat storage efficiency of the energy storage system under study is $73 \%$ and its optimum heat discharge efficiency is $85 \%$.

\section{References}

Abdoly, M.A., Rapp, D., 1982. Theoretical and experimental studies of stratified thermocline storage of hot water. Energy Convers. Manage. 22 (3), 275-285.

Al-najem, N.M., Al-marafie, A.M., Wzuddin, K.Y., 1993. Analytical and experimental investigation of thermal stratification in storage tanks. Int. J. Energy Res. 17, 7788.

Chen, K.S., Chen, Y.Y., Tsai, S.T., 1990. An experimental study of the heat transfer performance of a rectangular two-phase natural circulation loop. Exp. Heat Transfer 3, $27-47$.

Hariharan, K., Badrinarayana, K., Srinivasa Murthy, S., Krishna Murthy, M.V., 1991. Thermal stratification in hot-water storage tanks. Energy 16 (7), 977-982.

Hijikata, K., Hasegawa, H., Nagasaki, T., 1989. Study on a heat pipe using a binary mixture. Trans. JSME, Part B 55, 1469-1476.

Holman, J.P., 1992. Heat Transfer, seventh Ed. McGraw-Hill, New York.
Huang, B.J., Chen, S.L., Heieh, C.T., 1983. Experiment and simulation of thermosyphon collector. J. Chin. Inst. Chem. Eng. 14, 407-417.

Konev, S.V., Wang, J.L., Tu, C.J., 1995. Characteristics of a heat exchanger based on a collector heat pipe. Heat Recovery Syst. CHP 15 (5), 493-502.

Lavan, Z., Thompson, J., 1977. Experimental study of a thermally stratified hot water storage tanks. Solar Energy 19, 519-524.

McDonald, T.W., Hwang, K.S., Diciccio, R., 1977. Thermosiphon loop performance characteristics: Part 1. Experimental study. Trans. ASHRAE 83, 250-259.

Misra, R.S., 1994. Thermal stratification with thermosyphon effect in solar water heating systems. Energy Convers. Manage. 35 (3), 193-203.

Oppel, F.J., Ghajar, A.J., Moretti, P.M., 1986. A numerical and experimental study of stratified thermal storage. Trans. ASHRAE 92, 293-309.

Pluta, Z., Pomierny, W., 1995. The theoretical and experimental investigation of the phase-change solar thermosyphon. Renew. Energy 6 (3), 317-321.

Uhlemann, R., Bansal, N.K., 1985. Side-by-side comparison of a pressurized and a nonpressurized solar water heating thermosiphon system. Solar Energy 34 (4-5), 317-328.

Young, M.F., Bergquam, J.B., 1981. Performance characteristics of a thermosyphon solar domestic hot water system. J. Solar Energy Eng. 103, 193-200. 